\title{
Análises biplot na avaliação de cultivares de trigo em diferentes níveis de manejo
}

\author{
Giovani Benin (*); Cilas Pinnow; Cristiano Lemes da Silva; Eduardo Stefani Pagliosa; Eduardo \\ Beche; Elesandro Bornhofen; Lucas Berger Munaro; Raphael Rossi Silva \\ Universidade Tecnológica Federal do Paraná (UTFPR), Curso de Graduação em Agronomia e Programa de Pós-Graduação em \\ Agronomia, Rodovia PR 469, km 01, 85501-970 Pato Branco (PR), Brasil. \\ (*) Autor correspondente: benin@utfpr.edu.br
}

Recebido: 28/jun./2011; Aceito: 27/dez./2011

\section{Resumo}

O objetivo deste estudo foi avaliar o desempenho agronômico de cultivares de trigo em diferentes sistemas de manejo. Os experimentos foram realizados em Pato Branco (PR), nas safras agrícolas 2008 e 2009. O delineamento experimental foi o de blocos ao acaso em esquema fatorial, com três repetições. Os tratamentos consistiram de quatro níveis de manejo: controle (E1), tradicional (E2) e otimizados (E3 e E4), sendo diferenciados quanto ao nível de adubação química e ao controle de plantas daninhas, pragas e doenças. As metodologias em gráfico biplot AMMI e GGE foram utilizadas para a análise dos dados. Os níveis de manejo otimizados maximizaram o rendimento, principalmente quando os fatores meteorológicos não foram limitantes. Há diferença de adaptação entre cultivares e sistemas de manejo cultural. A cultivar BRS Guamirim adaptou-se aos níveis E3 e E4 em 2008, enquanto em 2009 associou-se a E1 e E2. Apenas as cultivares BRS Tangará (E1 e E2) e Pampeano (E3 e E4) mantiveram consistência de associação aos níveis de manejo, em ambos os anos. As técnicas biplot são eficientes em indicar cultivares mais adaptadas aos níveis de manejo cultural em trigo.

Palavras-chave: Triticum aestivum L., rendimento de grãos, GGE Biplot, AMMI.

\section{Biplot analysis of spring wheat genotypes grown under differing management levels}

\begin{abstract}
The objective of this study was to evaluate the agronomic performance of wheat cultivars under different management levels. Experiments were carried out in Pato Branco (PR), within crop years 2008 and 2009. The experimental design was randomized blocks in factorial scheme, with three replicates. Treatments consisted in four levels of management, control (E1), traditional (E2) and optimized (E3 and E4), distinguished by level of chemical fertilization and by control of weeds, pests and diseases. Methodologies in AMMI and GGE biplot graphics were used for data analysis. The levels of management maximized the wheat yield, especially when meteorological features were not limiting. Adaptability showed difference among cultivars in the crop managements. The BRS Guamirim cultivar showed adaptability to levels E3 and E4 in crop year 2008, whereas it was associated to E1 and E2 in crop year 2009. Only the cultivars BRS Tangará (E1 and E2) and Pampeano (E3 and E4) kept association consistency to traditional and optimized levels, in both years. Biplot techniques are efficient to indicate more adapted cultivars to levels of crop management in wheat.
\end{abstract}

Key words: Triticum aestivum L., grain yield, GGE Biplot, AMMI.

\section{INTRODUÇÃO}

O Brasil produz cerca de cinco milhóes de toneladas de trigo anualmente, o que corresponde à metade do seu consumo atual. O Estado do Paraná é responsável por mais da metade desta produção, porém com baixos patamares produtivos, oscilando entre 737 e $2728 \mathrm{~kg} \mathrm{ha}^{-1}$ na última década (CONAB, 2011). O aumento do rendimento da cultura é limitado por uma série de fatores, incluindo a falta de integração das abordagens genéticas e de manejo cultural.

Para maximizar a produtividade de grãos em nível de lavoura é de fundamental importância a utilização de tecnologias adequadas e identificaçấo de cultivares responsivas aos níveis tecnológicos de manejo disponíveis. Neste contexto, muitas vezes, predomina o empirismo, o que pode resultar em uma exploração inadequada da interação genótipo $\mathrm{x}$ ambiente.

De acordo com Carver (2009), a adoçáo de sistemas de manejo intensivos foi bem sucedida na elevação da produção de trigo nos EUA. Em estudos realizados por Pires el al. (2005; 2009), verificou-se que a otimização das técnicas de manejo foi eficiente em maximizar a produtividade de grãos, entretanto, com respostas variáveis dos genótipos aos manejos aplicados; as cultivares BRS Angico e BRS Guamirim, por exemplo, tiveram seu rendimento incrementado em $9 \%$ e $41 \%$ respectivamente. 
Nos últimos cinco anos foram disponibilizadas 40 cultivares de trigo aos triticultores brasileiros, sendo 32 indicadas para cultivo no Estado do Paraná (Brasil, 2011). Neste conjunto de cultivares há presença de variabilidade quanto ao potencial produtivo, estabilidade e responsividade às variações edafoclimáticas e de manejo (Albrecht et al., 2007; Caieráo et al., 2006; Franceschi et al., 2010). Dessa maneira, a escolha de cultivares adequadas demonstra ser uma prática de extrema importância.

A utilização de técnicas multivariadas aliada a análises gráficas, em complemento e/ou substituição a análises univariadas, facilita a observaçáo das interaçôes complexas que envolvem os dados de pesquisa agronômica (MA et al., 2004), permitindo melhor interpretação, e geração de informação resumida (Sena et al., 2002). Dentre as metodologias inovadoras de análise, a GGE biplot (genotype and genotype-by-environment) e a AMMI (additive main effects and multiplicative interaction analysis), possibilitam inferências quanto ao desempenho de genótipos e ambiente, com facilidade na visualização dos dados (Yan et al., 2000; YAn, 2002; Hassanpanah, 2010).

O objetivo do estudo foi avaliar o desempenho agronômico de cultivares de trigo em sistemas de manejo tradicionais e otimizados e, identificar, através de análises gráficas, cultivares mais responsivas e associadas aos níveis de manejo avaliados.

\section{MATERIAL E MÉTODOS}

O estudo foi realizado nos anos agrícolas 2008 e 2009 em Pato Branco, Paraná, em altitude de $730 \mathrm{~m}$, latitude de $26^{\circ} 41^{\prime} \mathrm{S}$ e longitude de $52^{\circ} 07^{\prime} \mathrm{W}$. O solo da área pertence à unidade de mapeamento LVdf2 - Latossolo Vermelho distroférrico textura argilosa, álico (BHERING et al., 2008), de clima predominante Cfa, segundo a classificaçáo de Köppen (МаAск, 1968).

Nos dois anos agrícolas, os tratamentos constaram de combinaçôes entre oito cultivares de trigo e quatro níveis de manejo, que representam a ampla gama de insumos e níveis de investimento utilizados pelos triticultores da regiâo, equivalentes a diferentes expectativas de produtividade. O delineamento experimental foi o de blocos ao acaso em esquema fatorial, com três repetiçôes, com a combinação dos fatores: cultivares de trigo (BRS 208, BRS 220, BRS Tangará, BRS Pardela, BRS Guamirim, CD 114, CD 117 e Pampeano) e níveis de manejo (controle E1, tradicional - E2, e otimizados - E3 e E4).

Os níveis de manejo foram: E1: Sem aplicação de insumos, apenas a semente. E2: Adubação de base com $100 \mathrm{~kg} \mathrm{ha}^{-1}$ da formulaçáo 08-16-16 (N-P-K), uma aplicação de inseticida metamidofós $\left(0,2 \mathrm{~L} \mathrm{ha}^{-1}\right)$ para o controle de pulgóes e uma aplicação de $0,75 \mathrm{~L} \mathrm{ha}^{-1}$ de fungicida tebuconazol, no início do florescimento. E3: Tratamento de sementes com 0,27 L $100 \mathrm{~kg}^{-1}$ de sementes do fungicida triadimenol, adubação de base com $230 \mathrm{~kg} \mathrm{ha}^{-1}$ da formulação 08-20-20 (N-P-K), $80 \mathrm{~kg} \mathrm{ha}^{-1}$ de nitrogênio em cobertura, na forma de uréia, aplicado no início do perfilhamento, uma aplicação de 6,6 $\mathrm{g} \mathrm{ha}^{-1}$ do herbicida metsulfurom-metílico, uma aplicação de $0,1 \mathrm{~L} \mathrm{ha}^{-1}$ do inseticida lufenuron, uma aplicação de 0,2 L e 0,3 $\mathrm{L} \mathrm{ha}^{-1}$ do inseticida metamidofós e uma aplicação do fungicida azoxistrobin+ciproconazol, respectivamente, no início do florescimento, uma aplicação de $0,75 \mathrm{~L} \mathrm{ha}^{-1}$ do fungicida tebuconazol no estádio de enchimento de grãos. E4: Tratamento de sementes

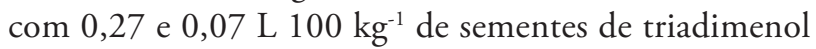
(fungicida) e imidacloprid (inseticida), respectivamente, adubação de base com $350 \mathrm{~kg} \mathrm{ha}^{-1}$ de 08-20-20, $120 \mathrm{~kg}$ $\mathrm{ha}^{-1}$ de nitrogênio em cobertura, na forma de uréia, dividida em duas aplicaçóes (início e final do perfilhamento), uma aplicação de $6,6 \mathrm{~g} \mathrm{ha}^{-1}$ do herbicida metsulfurom-metílico, uma aplicação de $0,1 \mathrm{~L} \mathrm{ha}^{-1}$ do inseticida lufenuron no início do florescimento, uma aplicação de $0,15 \mathrm{~L} \mathrm{ha}^{-1}$ do inseticida tiametoxam+lambda-cialotrina, uma aplicaçáo de $0,3 \mathrm{~L} \mathrm{ha}^{-1}$ do fungicida azoxistrobin+ciproconazol no início do florescimento e, com intervalos de 15 dias, duas aplicaçóes de $0,50 \mathrm{~L} \mathrm{ha}^{-1}$ do fungicida tebuconazol. O manejo e os tratos culturais foram efetuados conforme recomendaçôes técnicas da cultura (RCBPTT, 2008).

As parcelas foram compostas de sete fileiras de trigo de 5,0 m de comprimento, espaçadas em $0,17 \mathrm{~m}$, com densidade de 350 plantas aptas por $\mathrm{m}^{2}$, sendo a área útil formada pelas cinco fileiras centrais. Para a semeadura, em sistema de plantio direto, utilizou-se uma semeadora de parcelas experimentais marca Semina/Embrapa. As datas de semeadura foram, respectivamente, 2 e 6 de julho de 2008 e 2009, respeitando o zoneamento agrícola estabelecido pela recomendação de pesquisa.

Foram avaliados cinco caracteres: sendo dois aferidos em campo: a) número de afilhos férteis por metro linear (AFL), obtido pela contagem dos afilhos que emitiram espigas, em $2 \mathrm{~m}$ lineares de cada unidade de observação (linha); b) dias da emergência à maturação (DEM), tendo como referência a maturação fisiológica de mais de $50 \%$ das plantas da parcela; e três componentes do rendimento de grãos aferidos em laboratório: c) número de espiguetas por espiga (NE), considerado o número médio de espiguetas contados em 15 espigas, colhidas ao acaso em cada parcela; d) peso do hectolitro $(\mathrm{PH})$ que corresponde à massa de $100 \mathrm{~L}$ de grãos, expresso em kg $100 \mathrm{~L}^{-1}$; e) rendimento de grãos (RG), determinado pela colheita e trilha de todas as plantas da área útil da parcela, em gramas, corrigido pela umidade de $13 \%$ e transformado para $\mathrm{kg} \mathrm{ha}^{-1}$.

Os dados foram submetidos à análise de homogeneidade de variância (teste de Bartllet) e de normalidade (Lilliefors). Como as variâncias foram homogêneas e normais, procedeu-se às análises de variância, sem 
necessidade de transformação. A relação entre o maior e o menor quadrado médio residual dos ambientes $\left(\mathrm{QMr}^{+} / \mathrm{QMr}\right.$ ) foi inferior a sete, para os caracteres avaliados, possibilitando a utilização da análise conjunta dos dados, na qual se consideraram cultivares e níveis de manejo como fatores fixos e ano como aleatório. Para estas análises, utilizou-se o aplicativo computacional Genes (Cruz, 2001).

Havendo interaçôes significativas, a adaptação das cultivares aos níveis de manejo foi analisada pelos métodos AMMI (additive main effects and multiplicative interaction analysis) e GGE Biplot (genotype+genotype-by-environment). $\mathrm{O}$ método AMMI combina a análise de variância e a análise de componentes principais, para ajustar, respectivamente, os efeitos principais (genótipos e ambientes) e os efeitos da interação GxA (Zobel et al., 1988). O modelo da metodologia AMMI pode ser demonstrado por:

$$
Y_{i j}=\mu+g_{i}+a_{j}+\sum_{k=1}^{n} \lambda k \gamma_{i k a j k}+\rho_{i j} \varepsilon_{i j}
$$

Em que, $Y_{i j}$ é a resposta média do genótipo $i(\mathrm{i}=1$, $2, \ldots$, G genótipos) no ambiente $\mathrm{j}(\mathrm{j}=1,2, \ldots, \mathrm{A}$ ambientes); $\mu$ é a média geral dos ensaios; $\mathrm{g}_{\mathrm{i}}$ é o efeito $f i x_{\mathrm{o}}$ do genótipo $i$; $\mathrm{a}_{j}$ é o efeito fixo do ambiente $j ; \lambda_{k}$ é o k-ésimo valor singular (escalar) da matriz de interaçóes original (denotada por GA); $y_{\mathrm{ik}}$ é o elemento correspondente ao i-ésimo genótipo, no k-ésimo vetor singular coluna da matriz GA; $\alpha_{j k}$ é o elemento correspondente ao j-ésimo ambiente, no k-ésimo vetor singular linha da matriz GA; $\rho_{i j}$ é o resíduo associado ao termo (ga)ij da interação clássica do genótipo i com o ambiente j; $\varepsilon_{i j}$ é o erro experimental médio.

$\mathrm{Na}$ análise AMMI é indispensável identificar o número de eixos que serão empregados na análise, e para a representaçáo da média produtiva foi adotado o modelo AMMI1.

Também foi utilizado o método GGE Biplot, que considera o efeito do genótipo e da interação entre genótipos e ambientes (YAN et al., 2000). Neste método, apenas o efeito principal de genótipo e da GxE são importantes, devendo ser considerados concomitantemente. Considera-se que o efeito principal do ambiente náo é relevante na seleção de cultivares. O modelo GGE biplot náo separa $G$ da $G x E$ mantendo-os juntos em dois termos multiplicativos, que podem ser visualizado na seguinte equação.

$$
Y_{i j}-\mu-\beta_{j}=\lambda_{1} \xi_{1 j} \eta_{1 j}+\lambda_{2} \xi_{2 j} \eta_{2 j}+\varepsilon_{i j}
$$

Em que, $Y_{i j}$ é o rendimento esperado do genótipo $i$ no ambiente $j ; \mu$ é a média geral das observaçóes; $\beta_{j}$ é o efeito principal do ambiente $j ; \lambda_{1}$ e $\lambda_{2}$ são denominados escores principais e secundários dos componentes principais, $\mathrm{PC} 1$ e PC2, respectivamente; $\xi_{1 j}$ e $\xi_{2 j}$ são os autovetores do genótipo i para PC1 e PC2, respectivamente; $\varepsilon_{\mathrm{ij}}$ é o resíduo não explicado por ambos os efeitos.

\section{RESULTADOS E DISCUSSÃO}

Os resultados da análise de variância conjunta (Tabela 1) revelaram significância $(\mathrm{p}<0,05)$ para a interação tripla dos fatores cultivar $\mathrm{x}$ ano $\mathrm{x}$ nível de manejo (C x A x M) para todos os caracteres avaliados, indicando que as cultivares responderam de forma diferenciada aos níveis de manejo e anos de cultivo. Os coeficientes de variação oscilaram entre $0,73 \%$ e $8,5 \%$, conferindo boa precisão às estimativas preditas neste estudo.

$\mathrm{O}$ rendimento médio de grãos das oito cultivares de trigo nos quatro níveis de manejo cultural e

Tabela 1. Resumo da análise de variância conjunta, incluindo as fontes de variação, seus respectivos quadrados médios e significâncias, de

\begin{tabular}{|c|c|c|c|c|c|c|}
\hline \multirow{2}{*}{ Fontes de variação } & \multirow{2}{*}{ G.L. } & \multicolumn{5}{|c|}{ Quadrados médios } \\
\hline & & RG (kg ha ${ }^{-1}$ ) & PH (g) & NE & AFL & DEM \\
\hline$(B / A) / M$ & 16 & $601.738,1$ & 26,96 & 1,16 & 22,10 & 4,11 \\
\hline Anos (A) & 1 & $508.500 .517,74^{* *}$ & $390,81^{* *}$ & $3,20^{\text {ns }}$ & $756,04^{* *}$ & $453,25^{* *}$ \\
\hline Manejo (M) & 3 & $3.376 .634,32^{\text {ns }}$ & $59,10^{\text {ns }}$ & $83,74^{* *}$ & $4.686,93^{\text {ns }}$ & $424,60^{\text {ns }}$ \\
\hline Cultivares (C) & 7 & $9.496 .869,31^{\mathrm{ns}}$ & $37,13^{\text {ns }}$ & $29,75^{* *}$ & $5.556,29 * *$ & $284,13^{*}$ \\
\hline$A \times M$ & 3 & $2.352 .212,21^{\mathrm{ns}}$ & $128,48^{*}$ & $0,10^{\text {ns }}$ & $1.547,03^{* *}$ & $55,36^{* *}$ \\
\hline$C \times A$ & 7 & $3.758 .084,30^{* *}$ & $53,58^{*}$ & $2,31^{* *}$ & $356,35^{* *}$ & $54,75^{* *}$ \\
\hline$C \times M$ & 21 & $664.930,07^{\text {ns }}$ & $15,00^{\text {ns }}$ & $0,79^{\text {ns }}$ & $587,38^{*}$ & $37,35^{\mathrm{ns}}$ \\
\hline$C \times A \times M$ & 21 & $438.128,74^{* *}$ & $43,40^{* *}$ & $0,73^{* *}$ & $240,54^{* *}$ & $41,56^{* *}$ \\
\hline Resíduo (Erro) & 112 & $51.776,87$ & 21,43 & 0,15 & 12,76 & 0,79 \\
\hline Total & 191 & & & & & \\
\hline Médias & & $2.675,71$ & 70,02 & 15,29 & 95,25 & 120,44 \\
\hline CV (\%) & & 8,50 & 6,61 & 2,55 & 3,75 & 0,73 \\
\hline
\end{tabular}
oito cultivares de trigo, em função de quatro níveis de manejo nas safras agrícolas de 2008 e 2009. Pato Branco (PR), 2011

**, * e ns: Significativo a 1\%, 5\% e não significativo pelo teste F, respectivamente; G.L.: Graus de liberdade; CV: Coeficiente de variaçáo; RG: Rendimento de grãos (em kg ha-1); PH: Peso do hectolitro (em g); NE: Número de espiguetas por espiga; AFL: Número de afilhos férteis; DEM: Dias da emergência à maturação fisiológica. 
Tabela 2. Rendimento médio de grãos $\left(\mathrm{kg} \mathrm{ha}^{-1}\right)$ de oito cultivares de trigo, listadas para quatro níveis de manejo cultural nas safras agrícolas de 2008 e 2009. Pato Branco (PR), 2011

\begin{tabular}{lcccccccccc} 
Cultivares & 2008E1 & 2008E2 & 2008E3 & 2008E4 & 2009E1 & 2009E2 & 2009E3 & 2009E4 & Média \\
\cline { 2 - 10 } BRS 208 & 726 & 952 & 1126 & 1224 & 2506 & 3239 & 4110 & 4862 & 2343 \\
BRS 220 & 412 & 730 & 1167 & 1426 & 3089 & 3799 & 3962 & 4595 & 2397 \\
BRS Tangará & 1073 & 1142 & 1376 & 1179 & 3401 & 4076 & 4666 & 5754 & 2833 \\
BRS Pardela & 621 & 1087 & 1224 & 1289 & 3226 & 4142 & 4989 & 6501 & 2885 \\
BRS Guamirim & 708 & 991 & 1300 & 1329 & 3840 & 4558 & 5220 & 6595 & 3068 \\
CD 114 & 579 & 985 & 1353 & 1177 & 2213 & 3527 & 4100 & 5162 & 2387 \\
CD 117 & 521 & 890 & 1020 & 1176 & 2934 & 3461 & 3747 & 4851 & 2325 \\
\hline Pampeano & 790 & 1104 & 1413 & 1453 & 3369 & 4600 & 5477 & 7130 & 3167 \\
\hline Média & 679 & 985 & 1247 & 1282 & 3072 & 3925 & 4534 & 5681 & 2676
\end{tabular}

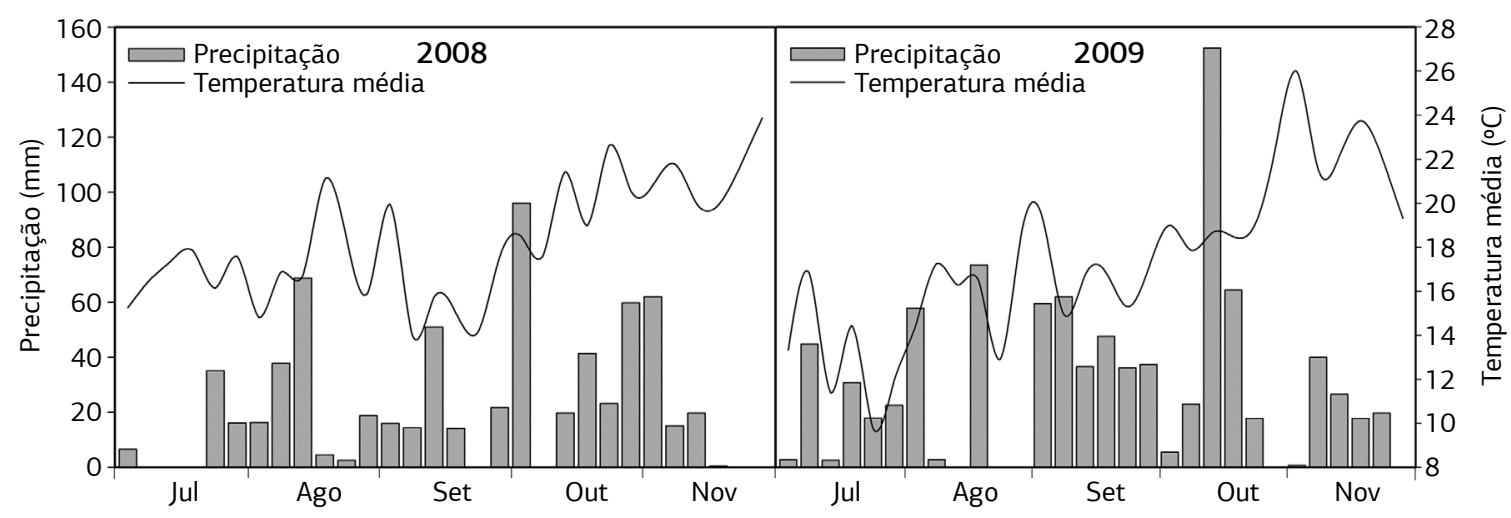

Figura 1. Precipitação pluvial e temperatura média referentes ao período experimental de 2008 e 2009 para o município de Pato Branco (PR), com dados agrupados de cinco em cinco dias.

safras agrícolas é apresentado na tabela 2. Observase presença de variabilidade genética entre cultivares quanto ao potencial produtivo e a responsividade aos níveis de manejo aplicados. As informaçóes contidas na tabela 2 são apresentadas graficamente pelo método biplot AMMI1 (Figura 2a,b,c), em que é possível fazer inferências quanto ao desempenho de genótipos, níveis de manejo e anos de avaliação, com facilidade na visualizaçáo dos dados e confiabilidade de representação que variou entre $97 \%$ e $99 \%$.

O efeito do ambiente, neste estudo, resultante do efeito principal dos níveis de manejo aliado às condiçôes edafoclimáticas ocorridas durante o periodo de cultivo contribuíram com 75\% (2008) e 69\% (2009) da explicação da variação total do rendimento de grãos (Figura 2a,b).

$\mathrm{Na}$ análise conjunta, o efeito do ambiente explicou $73 \%$ da variação total do rendimento de grãos (Figura 2c). Esse resultado indicou que, proporcionalmente, a variabilidade das condiçóes climáticas entre anos (Figura 1) e níveis de manejo foi superior ao efeito de principal de cultivares e interações. YAN (2001) afirma que, em ensaios realizados em diferentes condiçôes edafoclimáticas, geralmente, $80 \%$ da variação do rendimento é causada pelo ambiente, enquanto o genótipo e a interação genótipo $\mathrm{x}$ ambiente participam com aproximadamente $10 \%$ cada um.

Nos anos agrícolas de 2008 e 2009 (Figura 2a,b), respectivamente, observa-se que os níveis de manejo E1 e E2 estáo localizados abaixo da média produtiva geral, indicado pelo centro das linhas perpendiculares, com independentemente do ano agrícola, menor desempenho do RG. Ao contrário, os níveis de manejo E3 e E4 estão localizados acima da média produtiva geral, entretanto, sem estratificá-los no ano agrícola de 2008, fato este relacionado, principalmente, à menor disponibilidade hídrica (Figura 1). Na análise conjunta (Figura 2c), observou-se a formação de dois grupos, sendo o primeiro abaixo da média produtiva geral, que incluiu todos os níveis em 2008, sem estratificá-los. O segundo grupo foi localizado acima da média geral, onde foram agrupados os níveis de manejo de 2009, os quais foram ordenados em ordem decrescente de rendimento (E4, E3, E2, E1).

A porcentagem de explicaçáo acumulada para o ano agrícola de 2008 foi de 89,3\% (Figura 3a), e em 2009 de $98,7 \%$ (Figura 3b). Tais valores conferem elevada confiabilidade na explicação da variaçáo total do desempenho do genótipo, mais a interaçáo com o ambiente (G+GxA). Assim, a resposta produtiva das cultivares de trigo quanto 
(a)

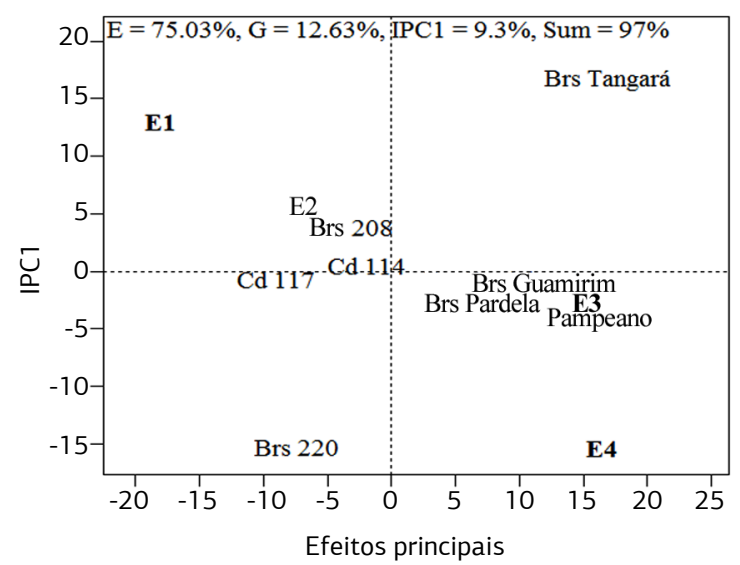

(b)
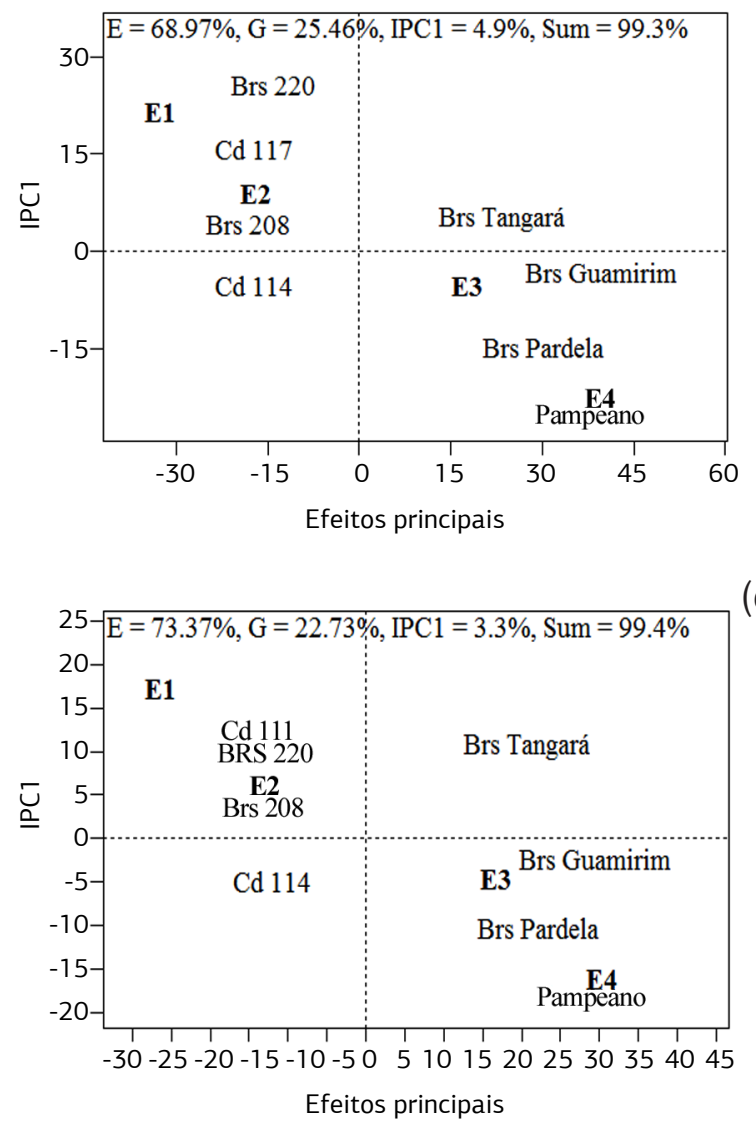

Figura 2. Plotagem dos escores do efeito principal dos genótipos e ambientes em funçâo do primeiro componente principal (IPC1), segundo o modelo AMMI1, para o caractere rendimento de grãos de oito cultivares de trigo, em quatro níveis de manejo, nas safras agrícolas de 2008 (a), 2009 (b) e conjunta (c). Pato Branco (PR).

aos níveis de manejo podem ser explicadas pelo padrão retido nas análises gráficas (MA et al., 2004).

$\mathrm{Na}$ análise de adaptabilidade, os quatro níveis de manejo foram agrupados em dois setores adaptativos semelhantes, interação não cruzada ou previsível, em ambos os anos, sendo: Setor 1: E3 e E4 e Setor 2: E1 e E2 (Figura 3a,b). No ano agrícola de 2008, considerando

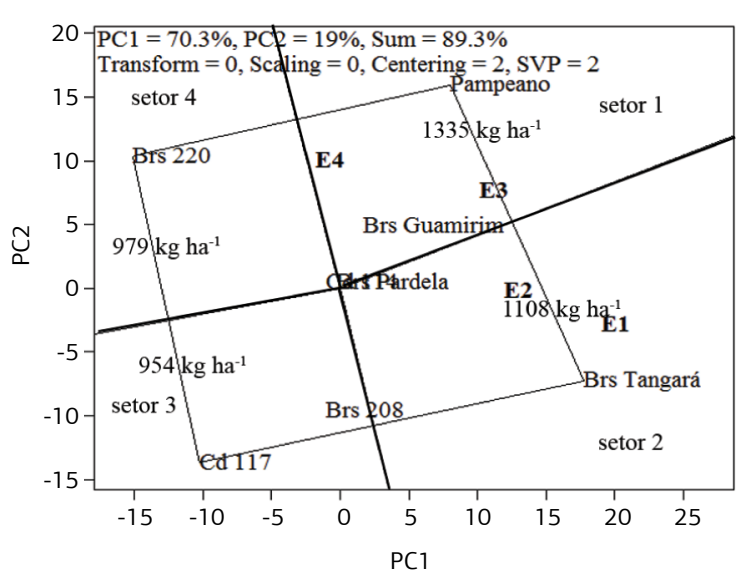

(a)

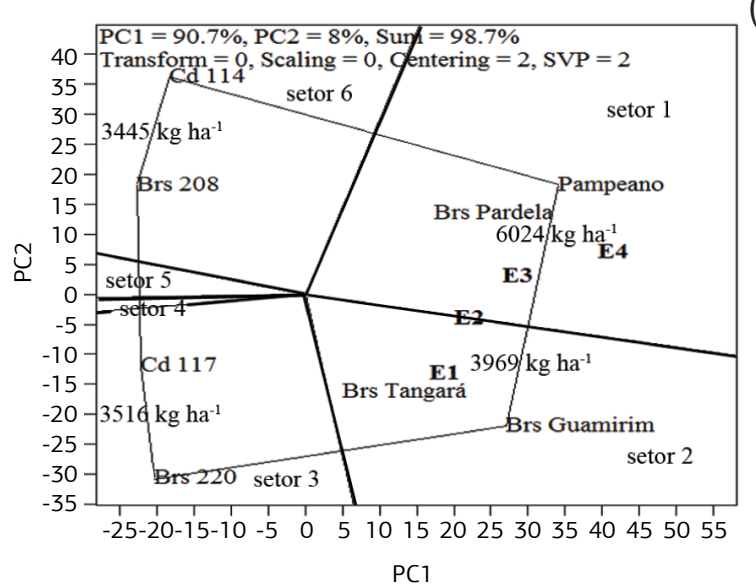

(b)

Figura 3. Plotagem dos escores dos componentes principais quanto à indicação de níveis de manejo com médias setoriais de rendimento obtidas pelos níveis de manejo e cultivares presentes em cada setor, segundo o modelo GGE Biplot, do caractere rendimento de grãos de oito cultivares de trigo, avaliadas em quatro níveis de manejo, em 2008 (a) e 2009 (b). Pato Branco (PR).

a média produtiva das cultivares nos níveis de manejo aos quais se associaram, observa-se que o rendimento de grãos oscilou entre $1108 \mathrm{~kg} \mathrm{ha}^{-1}$ (Setor 2) e $1335 \mathrm{~kg} \mathrm{ha}^{-1}$ (Setor 1), com um incremento de $20 \%$ no rendimento de grãos. Resultados semelhantes foram observados por Pires el al. (2005), quando verificaram que o manejo otimizado em comparação ao tradicional, proporcionou, na média de seis cultivares, incrementos de $716 \mathrm{~kg} \mathrm{ha}^{-1}$ (24\%) no rendimento de grãos. Em 2009, cujas condiçôes meteorológicas foram mais adequadas para o desenvolvimento do trigo, a diferença de desempenho entre o setor $2=3969 \mathrm{~kg} \mathrm{ha}^{-1}$ e setor $1=6024 \mathrm{~kg} \mathrm{ha}^{-1}$ foi de $52 \%$, caracterizando elevada resposta do rendimento de grãos no manejo otimizado.

Ainda na figura 3, observa-se que apenas as cultivares BRS Tangará (E1 e E2) e Pampeano (E3 e E4) mantiveram-se positivamente associadas aos mesmos níveis de manejo, em ambos os anos de avaliação. Em 2008, a cultivar BRS Pardela foi alocada no centro do gráfico biplot 
e, em 2009, houve associação positiva com os níves E3 e E4. A cultivar BRS Guamirim, altamente responsiva ao incremento no manejo cultural (PIRES et al., 2005; 2009; SCHEEREN et al., 2007) foi positivamente associada aos níveis E3 e E4 em 2008 (Figura 3a) e E1 e E2 em 2009 (Figura 3b).

As cultivares localizadas nos vértices dos setores tiveram o melhor ou o pior desempenho no referido setor (YAN e Tinker, 2006). Neste contexto, as cultivares Pampeano e BRS Tangará em 2008 (Figura 3a) e Pampeano e BRS Guamirim em 2009 (Figura 3b) proporcionaram o melhor desempenho nos setores correspondentes. Por outro lado, as cultivares CD 117 e BRS 220 (2008) e BRS 220 e CD 117 (2009), também localizadas nos vértices, tiveram os piores desempenhos nos setores em que estão localizadas. Em ambos os anos, as cultivares CD 114, CD 117, BRS 208 e BRS 220 não se associaram com quaisquer níveis de manejo. Neste contexto, uma premissa da análise GGE Biplot é não associar cultivares a quaisquer ambientes quando a média for inferior à média de cada setor (YAN, 2001; YAN e KANG, 2003).

Maiores detalhes do desempenho do rendimento de grãos em relaçãos aos níveis de manejo podem ser observados nas figuras 4 e 5, ano agrícola de 2008 e 2009 respectivamente. Nesta análise, traçou-se uma linha cruzando a origem do biplot e, ao longo desta, as cultivares foram ranqueadas em relação ao desempenho em cada nível de manejo (Yan e Tinker, 2006). O método ordenou com exatidão o desempenho dos genótipos em cada ambiente, quando comparados os gráficos biplot à tabela 1. Em 2008 (Figura 4), visualizaram-se as cultivares mais associadas aos níveis de manejo E1 (BRS Tangará) E2 (BRS Tangará e Pampeano), E3 (Pampeano, BRS Tangará e BRS Guamirim) e E4 (Pampeano, BRS 220 e BRS Guamirim). Em 2009 (Figura 5), apenas as cultivares BRS Guamirim, Pampeano, BRS Pardela e BRS Tangará tiveram rendimento acima da média do gráfico biplot (Figura 5a,b,c,d). Destaca-se o melhor desempenho de BRS Guamirim em E1 e E2 e Pampeano em E3 e E4, confirmando o que foi observado na análise de setores da figura 3 , através do critério de megaambientes.

A associação do RG, peso do hectolitro $(\mathrm{PH})$, número de espiguetas por espiga (NE), número de afilhos férteis (AFL) e dias de emergência a maturação fisiológica (DEM), com os níveis de manejo E1, E2, E3 e E4 pode ser observada na figura 6a,c. A associação entre duas variáveis é observada pelo ângulo formado entre seus vetores. Há associação positiva quando o ângulo entre os vetores for $<90^{\circ}$, negativa se o ângulo for $>90^{\circ}$, e nula quando o ângulo for de 90 (Yan e Tinker, 2006).

(a)
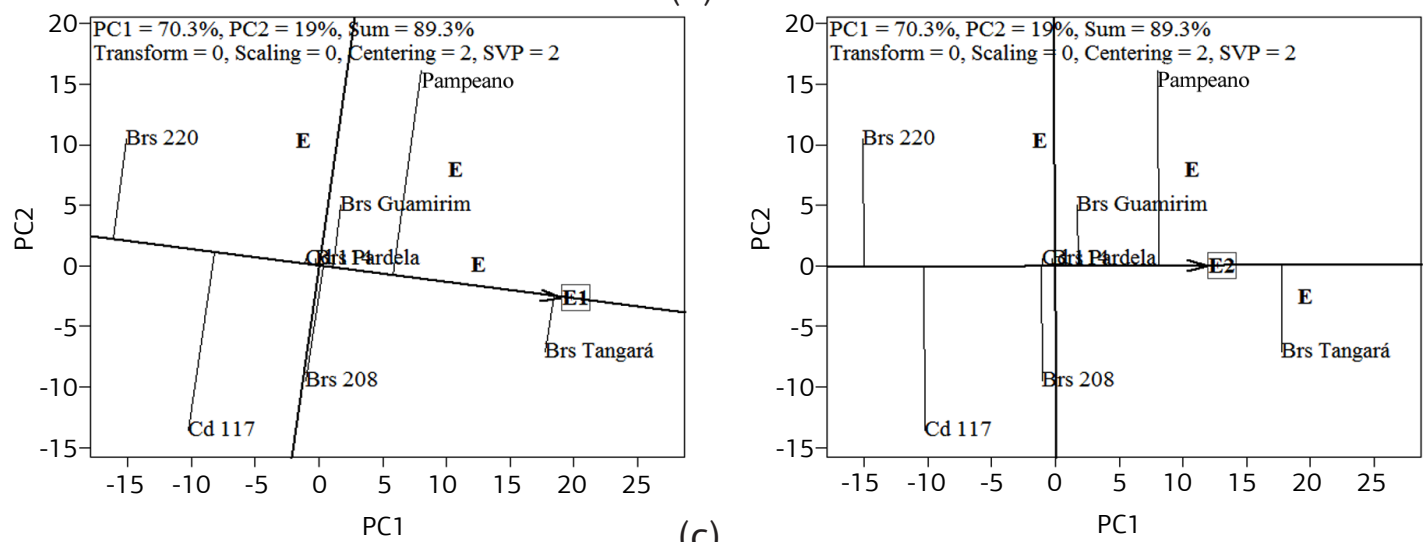

(b)

(c)
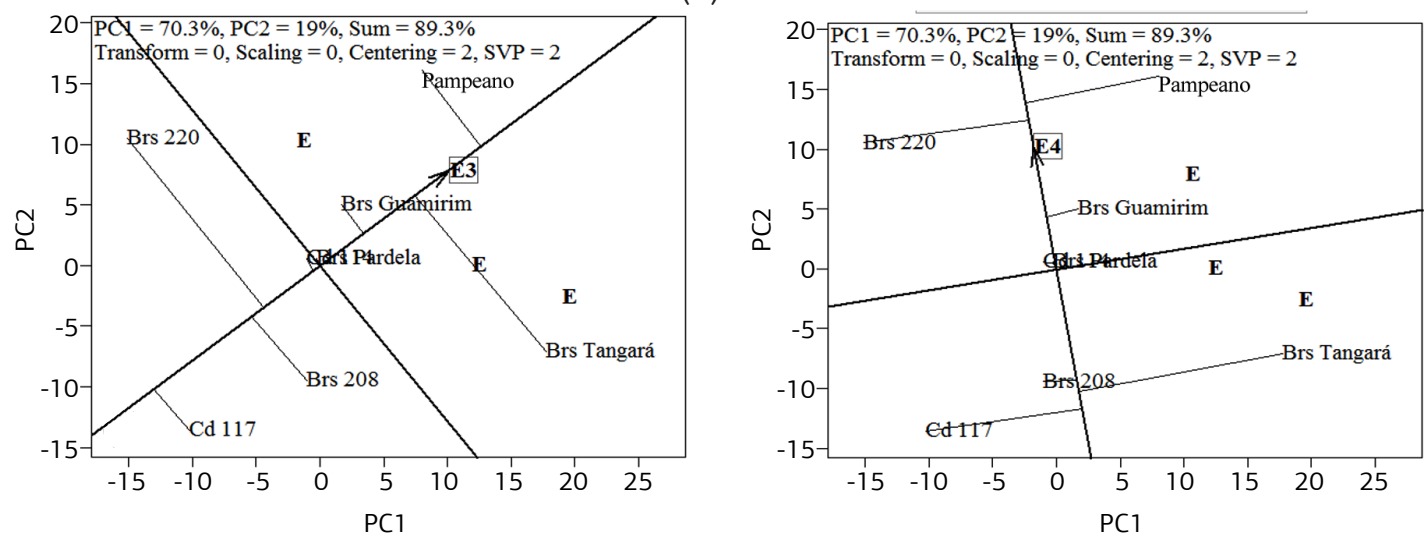

(d)

Figura 4. Plotagem dos escores dos componentes principais quanto à classificação dos genótipos com base em seu desempenho nos níveis de manejo, individualmente, segundo o modelo GGE Biplot, para o caractere rendimento de gráos de oito cultivares de trigo, avaliadas em quatro níveis de manejo, em 2008. Pato Branco (PR). 

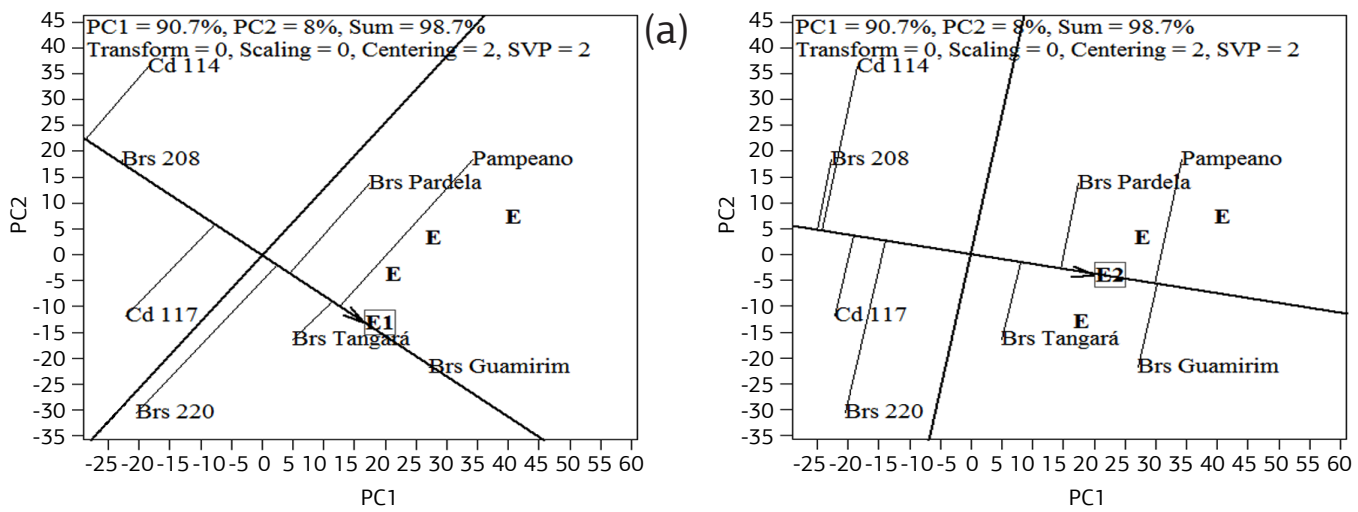

(b)

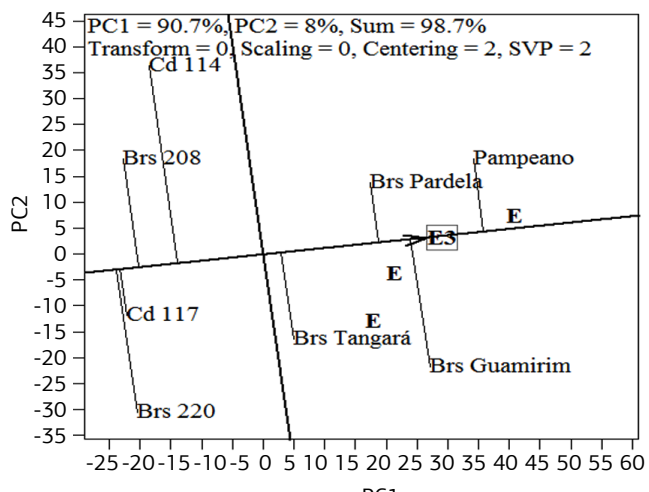

(c)

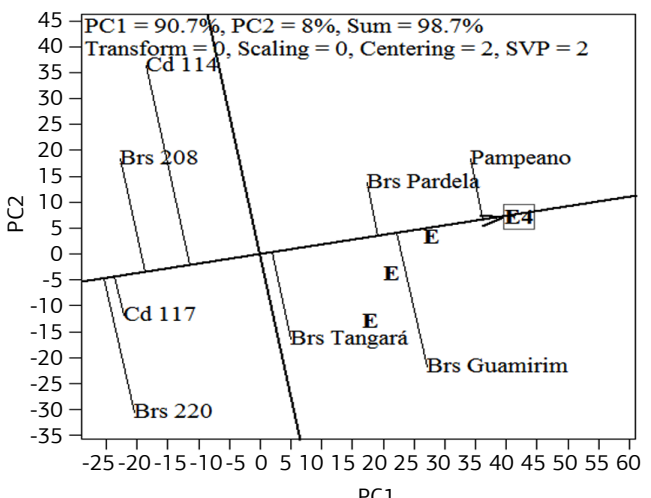

(d)

Figura 5. Plotagem dos escores dos componentes principais quanto à classificação dos genótipos com base em seu desempenho nos níveis de manejo, individualmente, segundo o modelo GGE Biplot, para o caractere rendimento de grãos de oito cultivares de trigo, avaliadas em quatro níveis de manejo, em 2009. Pato Branco (PR).

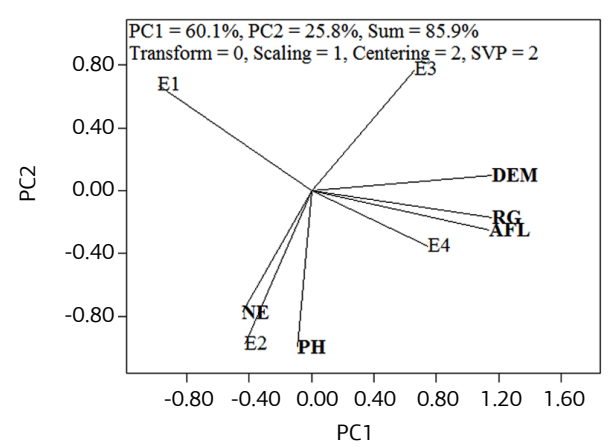

(a)

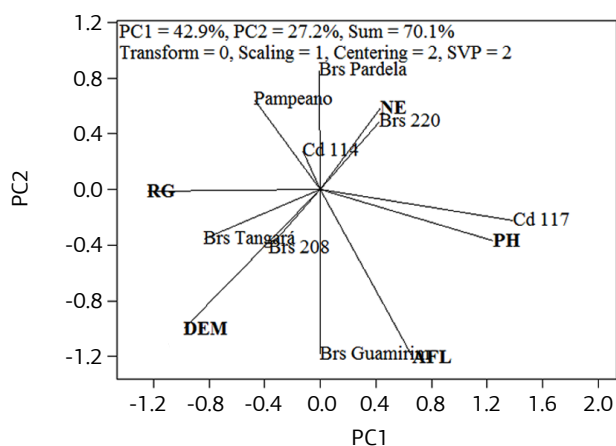

(b)
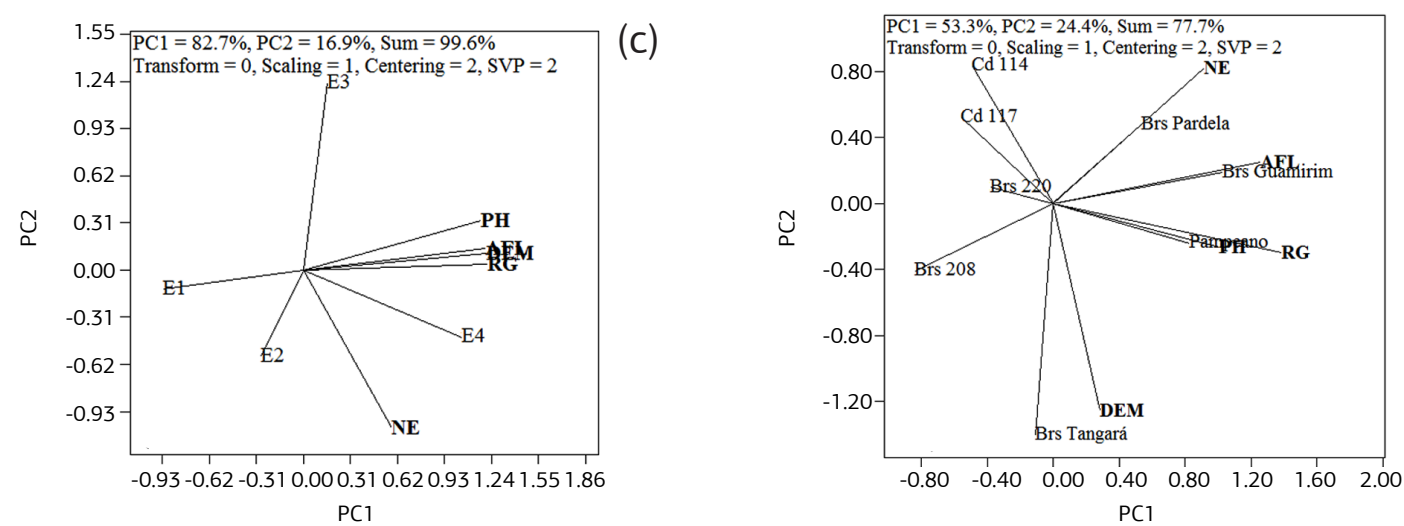

(d)

Figura 6. Plotagem dos escores dos componentes principais, segundo o modelo GGE Biplot, quanto à associação dos níveis de manejo (a e c) e cultivares (b e d) com os caracteres rendimento de grãos (RG), peso do hectolitro (PH), número de espiguetas por espiga (NE), número de afilhos férteis (AFL) e dias de emergência a maturaçấo fisiológica (DEM), em quatro níveis de manejo, em 2008 (a e b) e 2009 (c e d) em Pato Branco (PR). 
Por este critério, observou-se que em 2008 o RG foi associado com DEM e AFL, assim como estes caracteres tiveram maior média de desempenho com o nível E4. $\mathrm{O}$ peso do hectolitro e número de espiguetas por espiga associaram-se ao nível E2, o que pode ser atribuído a baixa associação do número de afilhos férteis ao nível E2. Menor número de afilhos férteis concorre na partição de fotoassimilados, havendo maior direcionamento para a definiçấo de mais espiguetas por espiga e enchimento de grãos.

No ano agrícola de 2009, todos os caracteres associaram-se positivamente com o nível E4, fato relacionado às condições meteorológicas não limitantes (Figura 1), permitindo a eles o melhor desempenho com o manejo otimizado. Quanto à associação dos caracteres com as cultivares, observou-se que, em ambos os anos, BRS Guamirim foi altamente associada e teve seu desempenho explicado pelo número de afilhos férteis (Figura 6b,d), aptidão destacada por Scheeren et al. (2007). Também, observou-se, em ambos os anos, associaçóes de elevada magnitude de BRS Tangará e BRS 208 com dias de emergência à maturação, e da cultivar Pampeano, com o rendimento de grãos.

As técnicas biplot foram eficientes em indicar as cultivares mais adaptadas aos níveis de manejo cultural, com riqueza de detalhes quanto ao desempenho das cultivares. Assim, é possível maximizar o potencial produtivo dessas cultivares, com lucratividade, e minimizar os riscos.

\section{CONCLUSÃO}

A adoção de níveis de manejo otimizados maximiza o potencial de rendimento de gráos do trigo, principalmente, em condiçôes meteorológicas favoráveis ao cultivo. A escolha do nível de manejo a ser adotado deve levar em consideração à resposta da cultivar aos insumos aplicados.

Independentemente do ano agrícola, a cultivar Pampeano é adaptada aos sistemas de manejo estabelecidos para otimizar o desempenho da lavoura, e BRS Tangará ao sistema de manejo cultural tradicional. As análises gráficas GGE Biplot e AMMI1 simplificam e facilitam a visualização dos dados e são eficientes em indicar cultivares adaptadas aos níveis de manejos.

\section{AGRADECIMENTOS}

Ao Conselho Nacional de Desenvolvimento Científico e Tecnológico e à Fundação Araucária, pelo apoio financeiro.

\section{REFERÊNCIAS}

ALBRECHT, J.C.; VIEIRA, E.A.; SILVA, M.S.; ANDRADE, J.M.V.; SCHEEREN, P.L.; TRINDADE, M.G.; SOARES SOBRINHO, J.; SOUSA, C.N.A.; REIS, W.P.; RIBEIRO JÚNIOR, W.Q.; FRONZA, V.; CARGNIN, A.; YAMANAKA, C.H. Adaptabilidade e estabilidade de genótipos de trigo irrigado no Cerrado do Brasil Central. Pesquisa Agropecuária Brasileira, v.42, p.1727-1734, 2007.

BHERING, S.B.; SANTOS, H.G.; BOGNOLA, I.A.; CÚRCIO, G.R.; MANZATTO, C.V.; CARVALHO JUNIOR, W.; CHAGAS, C.S.; ÁGLIO, M.L.D.; SOUZA, J.S. Mapa de solos do Estado do Paraná: legenda atualizada. Rio de Janeiro: EMBRAPA/ IAPAR, 2008. 74p.

CAIERÃO, E.; SILVA, M.S.; SCHEEREN, P.L.; DEL DUCA, L.J.A.; JUNIOR, A. N.; PIRES, J.L. Análise da adaptabilidade e da estabilidade de genótipos de trigo como ferramenta auxiliar na recomendação de novas cultivares. Ciência Rural, v.36, p.11121117,2006

CARVER, B.F., Wheat: Science and Trade. 1.ed. Iowa: WileyBlackwell. 2009. 569p.

CONAB. Séries históricas. Disponível em: <http://www.conab. gov.br>. Acesso em: 9/1/2011.

CRUZ, C.D. Programa Genes: Aplicativo computacional em genética e estatística. Viçosa: UFV, 2001. 648p.

FRANCESCHI, L.; BENIN, G.; MARCHIORO, V.S.; MARTIN, T.N.; SILVA , R.R.; SILVA, C.L. Métodos para análise de adaptabilidade e estabilidade em cultivares de trigo no Estado do Paraná. Bragantia, v.69, p.797-805, 2010.

HASSANPANAH, D. Analysis of GxE interaction by using the additive main effects and multiplicative interaction in potato cultivars. International Journal of Plant Breeding and Genetics, v.4, p.23-29, 2010.

MA, B.L.; YAN, W.; DWYER, L.M.; FREGEAU-REID, J.; VOLDENG, H.D.; DION, Y.; NASS, H. Graphic analysis of genotype, environment, nitrogen fertilizer, and their interactions on spring wheat yield. Agronomy Journal, v.96, p.169-180, 2004.

MAACK, R. Geografia Física do Estado do Paraná. Banco do Desenvolvimento do Paraná. Curitiba: UFPR / IBPT, 1968. 350p.

PIRES, J.L.F.; LIMA, M.I.P.M.; VOSS, M.; SCHEEREN, P.L.; WIETHÖLTER, S.; CUNHA, G.R.; IGNACZAK, J.C.; CAIERÃO, E. Avaliação de cultivares de trigo em sistema de manejo tradicional e otimizado, Passo Fundo, 2004. Passo Fundo: Embrapa Trigo, 2005. 19p. (Embrapa Trigo. Documentos Online, 54). Disponível em: http://www.infoteca.cnptia.embrapa.br/ handle/doc/852508. Acesso em: 8/1/2011.

PIRES, J.L.F.; SANTOS, H.P.; SCHEEREN, P.L.; MIRANDA, M.Z.; DE MORI, C.; CASTRO, R.L.; CAIERÃO, E.; PILAU, J. Avaliação de cultivares de trigo em diferentes níveis de manejo na regiáo do Planalto do Rio Grande do Sul. Passo Fundo: Embrapa Trigo, 2009. 23 p. (Embrapa Trigo. Boletim de pesquisa 
e desenvolvimento online, 74). Disponível em: http://www.cnpt. embrapa.br/biblio/bp/p_bp74. Acesso em: 10/1/2011.

RCBPTT - REUNIÃO DA COMISSÃO BRASILEIRA DE PESQUISA DE TRIGO E TRITICALE, 2., 2008, Passo Fundo. Informaçôes técnicas para a safra 2009: trigo e triticale. Passo Fundo: Comissão Brasileira de Pesquisa de Trigo e Triticale: Embrapa Trigo: Embrapa Transferência de Tecnologia, 2008. 172p.

SENA, M.M.; FRIGHETTO, R.T.S.; VALARINI, P.J.; TOKESHI, H.; POPPI, R.J. Discrimination of management effects on soil parameters by using principal component analysis: a multivariate analysis case study. Soil and Tillage Research, v.67, p.171-181, 2002.

SCHEEREN, P.L.; CAIERÃO, E.; SÓ e SILVA, M.; DEL DUCA, L.J.A.; NASCIMENTO JUNIOR, A.; LINHARES, A.; EICHELBERGER, L. BRS Guamirim: cultivar de trigo da classe pão, precoce e de baixa estatura. Pesquisa Agropecuária Brasileira, v.42, p.293-296, 2007.
YAN, W. GGEbiplot - A Windows application for graphical analysis of multi-environment trial data and other types of two-way data. Agronomy Journal, v.93, p.1111-1118, 2001.

YAN, W. Singular value partitioning for biplot analysis of multienvironment trial data. Agronomy Journal, v.94, p.990-996, 2002.

YAN, W.; HUNT, L. A.; SHENG, Q.; SZLAVNICS, Z. Cultivar evaluation and mega-environment investigation based on GGE biplot. Crop Science, v.40, p.597-605, 2000.

YAN, W.; KANG, M.S. GGE Biplot analysis: a graphical tool for breeders, geneticists, and agronomists. Flórida: Boca Raton, 2003.

YAN, W.; TINKER, A. Biplot analysis of multi environment trial data: principles and applications. Canadian Journal of Plant Science, v.86, p.623-645, 2006.

ZOBEL, R.W.; WRIGHT, M.J.; GAUCH, H.G. Statistical analysis of a yield trial. Agronomy Journal, v.80, p.388-393, 1988. 